\title{
Cultural Broker: A Necessity of Cross-Culture Communication*
}

\author{
ZHAO Hong-juan \\ Qingdao University of Science and Technology, Qingdao, China
}

\begin{abstract}
Cultural brokers who not only can estimate and understand their own cultures and values but also can communicate in a cross-culture communication proficiently and skillfully can undertake the jobs of mediator, advocator, interpreter, and educational consulter in cross-culture settings. In the study, the concept and functions of cultural brokers, the ways how to find and use cultural brokers and cultural broker using example- - IFI are examined, which come into the conclusion that cultural broker is the necessity of cross-culture communication.
\end{abstract}

Keywords: cultural broker, cross-culture communication, functions

\section{Introduction}

As the number of students studying abroad increases and the development of economy and culture in all of the world, cultural brokers play a more active and meaningful role in the process of cross-culture communication. During the cross-culture communication, the barrier and difficulties encountered by resource people demonstrate there is a shock or conflict between what they are familiar and unfamiliar. Therefore, it is meaningful to study the needs of cultural brokers and the ways that how to get and use cultural brokers, and in this paper, a case study will be provided to prove the necessity of cultural brokers in a cross-culture environment.

\section{Who Are Cultural Brokers?}

The concept of "cultural brokering" as used by Herzog best describes the way in which this conflict can be resolved (Wyatt, 1978). Richard Kurin examined and concluded that cultural brokers like other types of brokers, enable important transactions, interrelationships, and exchanges, and also pointed out that cultural brokers study, understand, and represent someone's cultural (even their own) to no nonspecialized others through various means and media.

After the appearance of cultural brokers, in education and communication setting, cultural broker model grows popular in educationalists and scholars. At the beginning, the cultural broker model describes a method of operation that empowers all students to become involved in the campus community. Some scholars by comparing abstract versus concrete statistics pointed out the cultural broker encompasses four components: learning to think contextually, boundary spanning, ensuring optimum performance, and taking action. As Fleming (1984) figured out: "current trends are still dictated by expectations so old that they are no longer conscious" (p. 139), so to step outside the cultural points means to believe in other and explore their perspectives and views, in addition, cultural

\footnotetext{
* Acknowledgements: This article is funded by Foreign Language and Research Press (No. 2015).

ZHAO Hong-juan, lecturer, M.A., Foreign Language School, Qingdao University of Science and Technology.
} 
brokers need to make these trends conscious, explore meaning for themselves and their students, and broaden the interpretation to include all cultures and groups.

\section{The Needs for Cultural Brokers in Cross-Cultural Setting}

Before investing the function of cultural broker, the crying needs and basic necessity of cultural brokers should be considered, and in this study we list the situation that a cultural broker may be urgent.

- The new arrivals reach in a complete recency setting and are unfamiliar with local language and culture. Especially for the kids who do not completely understand the meaning culture and so need the assistance of those who can stand in the gap in both passport country, and the new country he who lives now.

- The new arrivals hope to set up a closed and harmonious relationship with people in target culture. It is a so hard thing for the adults who want to adapt to a new culture; the deep understanding of the passport country is a great block for them to get an idea of a different culture, and the incompatibility may make him restless. However, the appearance of a culture broker allows him to release the pressure, as soon as possible to understand and adapt to the local culture.

- People in target culture wish conduct and carry out the corresponding instruction to new arrivals to help them integrate with local culture rapidly. Anyone who has lived in foreign countries or know about the immigrant experience can understand the importance of cultural brokers who are very kind and gentle. Because of this need, many locals are willing to take on the role of the cultural messenger so that new entrants can be integrated into the local cultural life as soon as possible to create a more harmonious environment and society together.

- If there is an ongoing basis, the cultural brokers will be needed to provide information, support, and other services over a long time. To adapt and learn a culture cannot be done overnight, but need long-term efforts and persistence, in this case the importance and urgency of the culture broker is obvious. For new immigrants or new arrivals, culture brokers are not only new culture introducer, but also the long-term supporters and helpers to help others adapt anew life.

\section{Ways to Find and Use Cultural Brokers}

In the first part, the concept of cultural brokers has been studied based on that, the basic functions of cultural brokers can be conducted that they are mediator, advocator, interpreter, and educational consulter. Consider a foreigner who knows a familiarity with language game in that culture, he has no way "to go on" in a situation, and at this time, the cultural brokers functions will be highlighted (Quinn, 2003).

In order to guard against potential biases, culturally uneasy situations and conflicts of interests, the potential cultural brokers' background information including personal and professional experience, role in the community and the relationship with the cross-cultural communicators. Regarding the concrete ways for the cultural brokers finding, the following facts should be considered:

- Cultural brokers should learn to think contextually. In order to meet diverse needs of cross-cultural communicators, a cultural broker should be aware of their beliefs and dialogues with others and can be focus on recognizing and appreciating the different cultures between his or her own and cross-cultural communicator's.

- Consider proficiency in speaking, reading, and writing. If cultural brokers are appropriate and qualified, they can support cross-cultural communicator, especially in educational background where they can support 
teachers and educational professionals in their work with students from culturally and linguistically diverse background. Concretely, the cultural brokers can help cross-cultural communication overcome diversely cultural shock by supply culture, folklore, habits, and language of target country.

- Cultural brokers should provide some specific ways to help new arrivals. In order to set up a close relationship with their "clients", the ways for the help supporting should be considered, such as, cultural brokers can help and encourage the new arrivals to take part in social events that are unfamiliar to the new, set up workshop and language study groups for them, and so on.

\section{An Example of Cultural Brokers: IFI Support}

IFI, international friendships, is an international friendship association of Ohio, which supports airport pick, temporary housing ,and other helps to the new arrival students or visiting scholars of the Ohio state university. IFI sponsors various activities that allow you to experience the best of American culture and develop friendship. There are monthly culture cuisine, join a group of Americans for a dinner party, where the new arrivals can enjoy sample American cuisine, culture, games, and all aspects of American family. In addition, IFI will hold the English corner every week; by having an English conversation partner, the new arrivals can have a deeper cultural experience with a native English speaker while they are in the new culture. In the Columbus area, the persons who just know about his passport culture will be matched with an individual with whom you can enjoy occasional meals or have relax conversations together, which is a way to experience and know about a new culture.

The case study involved in two students from China, XIA and YANG who enrolled in OSU of United States and both of them has no experience and little knowledge with American culture. IFI regards cultural brokers are necessary for the new students from overseas as they can provide following help.

- Know about the students' educational history and life experience in China;

- Know about the similarities and differences between American and China;

- Develop proper instructions, strategies, and materials to live in America;

- Improve their language level to adapt to the college study quickly.

Before arriving in the United States, XIA had found a host family with the help of IFI, so just she was off the airplane, host family owner Paul and hostess Diane warmly greeted her. Diane is a middle school teacher before retirement, and she has a young deeper understanding for people's psychology, the United States traditional culture, customs, etc.; Paul is passionate man before retirement and a 4S store manager. For their meeting, Paul and Diane gave XIA a big hug, which let her feel it seems to be home, rather than to a foreign country where a lot of people feel unfamiliar. When XIA got Paul and Diane's house, she felt so excited, as Diane made XIA's temporarily-bedroom decor so nice and warm, with Chinese ink-wash painting hanging on the wall and Chinese paper-cutting on the table, and the entire room décor is the perfect combination of Sino-American style.

According to XIA's lifestyle, Diane prepared some hot water for her which touched her most, although Diane has not understand why the Chinese people like to drink hot water. After dinner, PAUL and Diane had a pleasant conversation with XIA, because they knew the basic information and education status of XIA by IFI which makes her feel warm. Since then, in order to help XIA adapt the life of America as soon as possible, at every weekend, Paul and Diane took XIA to the local supermarkets and other shopping places; they hoped Xia 
could shop alone in future. They also took XIA to watch circus performances, which she previously saw only on television, but now she could experience by herself to understand the United States of this entertainment culture with the help of Paul and Diane. They also went to see a variety of sporting events such as baseball, rugby, NBA basketball, and so on. Under the introduction of Paul and Diane, XIA met a lot of friends of Paul and Diane. With so many American friends, XIA got used to American life quickly.

After XIA got used to American life gradually, her study and life went so well. During XIA's adaptation and understanding of American culture, Paul and Diane are very competent culture brokers, who play a vital role in the new arrivals' culture adaption.

On the contrary, as YANG was not self-confidence to his English, and did not love to communicate with strangers, culture brokers or host families could not have chance to give him so help to adapt the new culture. The result can be predictable, a year later, YANG still could not have a good understanding of local cultural practices and culture and it was hard to become one part of local life.

\section{Conclusion}

With the help of cultural brokers, actually, the host family who pick up XIA from airport and provide temporary house for the first few days after XIA arrived in Columbus, and weekend house that is every Saturday Xia lives in her host family's house, Xia quickly adapt to the external environment and know about American cuisine, shopping habit, circus, baseball, religious, and so on. Reversely, YANG has not get any help of cultural broker, even if he continues his life in Columbus, and he is still like a new arrival just knowing about very little local culture; in addition, he frequently makes some foolish mistakes because of the cultural knowledge lacking.

In a word, culture brokers are important assistants of newcomers to adapt a new culture in a new life. With the economic development and the frequent communication of culture in countries, people have much more chances to emigrant and study abroad, in which case, there is even more needs of culture brokers who have a wealth of knowledge in language and culture and are willing to put enthusiasm for newcomers to help them adapt the new life. At the same time, if new arrivals can accept the help of culture brokers sincerely, it is supposed that they will be able to quickly and well into the local life.

\section{References}

Fleming, J. (1984). In college: A comparative study of students' success in black and in white institutions (1st ed., p. 139). San Francisco: Jossey-Bass.

New directions for student services. (1992). The cultural broker: A role for student affairs educators (pp. 57-64). Wilmington: Wiley Periodicals, Inc..

Quinn, C. J. (2003). Acts of reading: Taking it from the top-The growth and care of genre (pp. 38-60). Hawaii: University of Hawaii Press.

Richard, K. (1997). Reflection of a cultural broker: A view from the Smithsonian. Washington, D.C.: Smithsonian Institution Press.

Tettegah, S. Y. (2005). Technology, narratives, vignettes, and the intercultural and cross-cultural teaching portal. Urban Education, $40,368$.

Wyatt, J. D. (1978). Native involvement in curriculum development: The native teacher as cultural broker. Interchange, 9(1), $17-28$.

Wyatt, J. D. (1978-1979). Native involvement in curriculum development: The native teacher as cultural broker. Interchange: A Journal of Educational Studies, 9(1), 17-28. 